\title{
From the Guest Editor
}

It is an honor to serve as the guest editor for this first of two special issues of WORK: A Journal of Prevention, Assessment and Rehabilitation that focus on ergonomics issues concerning young people. This issue is dedicated to the memory of Cheryl Bennett, whose passion and profession merged in her efforts to educate parents, teachers, school administrators, and her fellow ergonomists about the importance of applying ergonomics principles to the work of children and the design of learning environments. The articles in this issue provide an interesting cross-section of current research concerning youths and ergonomics, from authors around the world.

In their two companion papers in this issue, Benedyk, Woodcock, and their colleagues describe and demonstrate the application of a new theoretical model of educational ergonomics. Models are important tools for facilitating and improving our understanding of how various systems work, and what may help them work better. In this new model, the system under study is the learning environment. The authors demonstrate the versatility of their model by discussing its application to the design-related learning needs of two different populations - university students and children with special needs.

One of the most interesting aspects of ergonomics is its multidisciplinary nature. Heyman and Dekel share with us information about a new educational program that links ergonomics with physical education class, as a means for helping elementary school students learn to integrate ergonomics principles into their daily activities. As stated in their abstract, "We believe that educating towards a balanced-posture, body-function and movement patterns, as well as their ergonomic implications, can minimize and even prevent these [musculoskeletal and back pain] problems."

Musculoskeletal discomfort in children is addressed in several of the papers in this issue. What children believe about musculoskeletal discomfort and its connection to various activities is the topic of the contribution to this issue by Coleman and Straker. Widely discussed in the popular press is the activity of wearing a backpack and potential links with back pain in chil- dren. Hazel provides a review of the recent research literature on backpacks, particularly focusing on three questions: 1) how much [load weight] is too much; 2) does adolescent back pain predict adulthood back pain; and 3) do certain behaviors lessen or increase risk of back pain? The question of backpack load limit is also addressed in the research paper in this special issue by Bauer and Freivalds. The authors use a mix of objective and subjective methods to investigate the question. Brackley, Stevenson, and Selinger's contribution to this special issue provides a detailed examination of the effects of backpack load and load location on forward lean and spine curvature in a sample of $10 \mathrm{yr}$ olds. Spine curvature was measured through the use of an instrumented backpack developed by the authors.

Five papers in this issue examine various aspects of students/youth and computer use, employing a variety of research methods and conducting studies in a range of settings, including school, laboratory, and home. Musculoskeletal discomfort associated with computer use and patterns of use (work postures, work-break patterns, etc.) are examined in several of the studies, and readers should find it interesting to compare the findings across the studies. Noack-Cooper, Sommerich, and Mirka present results from a survey of patterns of computer use and musculoskeletal discomfort in a sample of graduate and undergraduate university students; they also compare these patterns with results from a similar survey of computer using adult professional workers. In both samples, awkward postures adopted while using computers were statistically associated with musculoskeletal discomfort. Just what postures are adopted by $15-17$ yr olds while using computers in school, is the focus of the study by Kelly, Dockrell, and Galvin, who used surveys and observational techniques in performing their assessments. In a laboratory setting, Maslen and Straker quantitatively measured posture, as well as muscle activity, in their examination of similarities and differences between children and adults working at a computer. Kimmerly and Odell report their findings of young people's postures and other characteristics while using computers at home. They also report on parents' primary concerns and perceptions regarding their 
children's at-home use of computers. Appropriate postures, computer workstation set-up, and break patterns are some of the healthy computing concepts introduced to middle school students in the longitudinal study by Jacobs, Hudak, and McGiffert. These authors report a positive effect of the intervention, based on a reduction in prevalence of musculoskeletal discomfort across the three year study.

We hope this special issue will both inform and inspire readers of WORK. Reports contained in this issue are consistent with prior research that has found that young people do experience musculoskeletal discomfort, and that it is associated with certain activities that many children perform on a regular basis. The reports provide examples of a variety of research methodologies that can be used when studying children. Some of the reports identify voids in the knowledge base that should be seen by readers as opportunities for future investigation, while other reports in this issue provide evidence that models and interventions grounded in sound ergonomics principles can be effective in brining about positive changes in the learning environments in which children and youths work.

Guest Editor

Carolyn M. Sommerich, Ph.D.

The Ohio State University 1971 Neil Avenue

210 Baker Systems

Columbus, $\mathrm{OH} 43210$, USA

Tel.: +16142929965

Fax: +1 6142927852

E-mail: sommerich.1@osu.edu 